\title{
HER2 Blockade in Metastatic Collecting Duct Carcinoma (CDC) of the Kidney: A Case Report
}

\author{
Miguel H. Bronchud ${ }^{a}$ Sergi Castillo ${ }^{a}$ Santiago Escriva de Romanía \\ Santiago Mourelo ${ }^{b}$ Alejandra Fernández ${ }^{c}$ Cecilia Baena $^{d} \quad J$ esús Murillo \\ Joan C. Julia ${ }^{f}$ Jordi Esquius ${ }^{g}$ Rubén Romero ${ }^{h} \quad$ Xavier Andreu $^{h}$ \\ ${ }^{a}$ Department of Oncology, ${ }^{b}$ Department of Radiology, ${ }^{c}$ Department of Internal Medicine, ${ }^{d}$ Department of Palliative Care, \\ e Division of Endocrinology, Department of Internal Medicine, Hospital of Mollet, \\ ${ }^{\mathrm{f}}$ Department of Radiation Oncology, Hospital Plató, ${ }^{9}$ Department of Pathology, Hospital General of Granollers, \\ ${ }^{\text {h }}$ Department of Pathology, Hospital de Sabadell 'Parc Tauli', Barcelona, Spain
}

Keywords

Collecting duct carcinoma (CDC) - Bellini's tumor .

Double HER2 blockade · Lapatinib · Trastuzumab

\section{Summary}

Background: Collecting duct carcinoma of the kidney $(C D C)$ is a rare cancer associated with bad prognosis and, at present, with no specific effective therapies. Case Report: We report a clinical case with disseminated highgrade CDC presenting with widespread metastasis to both lungs, pelvic bones, axial skeleton, and the central nervous system (posterior fossa, both hemispheres and pituitary-hypothalamic). The primary tumor in the kidney was demonstrated (by fluorescence in situ hybridization and immunohistochemistry with Herceptest (3+ score)) to significantly overexpress HER2. Critically ill at presentation, the patient received oral capecitabine together with double HER2 blockade with both intravenous trastuzumab and oral lapatinib. His clinical response was a dramatic improvement and a progressive decline in the radiological size of all of his multiple cancer lesions. Conclusion: Double HER2 blockade is an effective therapy in disseminated CDC even in the presence of brain metastases.

\section{Introduction}

Collecting duct carcinoma (CDC) of the kidney, also known as Bellini's tumor, is a rare type of renal cancer, accounting for some $1 \%$ of all renal malignancies. It is usually very

\section{Schlüsselwörter}

Sammelrohrkarzinom · Ductus-Bellini-Karzinom . Doppelte HER2-Blockade · Lapatinib · Trastuzumab

\section{Zusammenfassung}

Hintergrund: Das Ductus-Bellini-Karzinom ist eine seltene Tumorerkrankung mit einer schlechten Prognose, für die es derzeit keine Standardtherapie gibt. Fallbericht: Wir berichten hier über einen Patienten mit hochgradigem Sammelrohrkarzinom mit Metastasierung in beide Lungenflügel und Hüftknochen, das Axialskelett und das zentrale Nervensystem (posteriore Fossa, beide Hemispheren und Hypophyse-Hypothalamus). Der Primärtumor in der Niere zeigte (in Fluoreszenz-in-situ-Hybridisierung und immunhistochemischer Untersuchung mit dem Herceptest (Score 3+)) eine starke Überexpression von HER2. Der zum Zeitpunkt der Aufnahme schwerkranke Patient erhielt orales Capecitabin zusammen mit einer doppelten HER2-Blockade mit intravenösem Trastuzumab und oralem Lapatinib. Er sprach an auf diese Therapie mit einer dramatischen klinischen Verbesserung und einer schrittweisen Verkleinerung aller Metastasen. Schlussfolgerung: Die doppelte HER2-Blockade ist eine effective Therapie beim disseminierten Sammelrohrkarzinom, selbst bei Vorliegen von Hirnmetastasen.

aggressive and associated with bad prognosis. Despite several published accounts on response to chemotherapies and targeted therapies, no standard treatment exists and it could be considered as an orphan disease where specific targets for treatment are urgently needed [1-5]. The Heidelberg

\section{KARGER}

Fax +497614520714

Information@Karger.de

www.karger.com (c) 2012 S. Karger GmbH, Freiburg

0378-584X/12/3512-0776\$38.00/0

Accessible online at:

www.karger.com/onk
Miguel H. Bronchud

Department of Oncology

Hospital of Mollet

Ronda dels Pinetons 8, Barcelona 08100, Spain

mhbronchud@telefonica.net 
histopathological classification published in 1997 categorized malignant parenchymal renal tumors into 4 subtypes: conventional clear cell, papillary, chromophobe, and collecting duct carcinomas [6]. The latter are characterized by irregular channels lined with atypical epithelium in an often inflamed desmoplastic stroma and have some genetic similarities to urothelial cancers [6]. These morphological and genetic similarities have led to the clinical use in small groups of patients of chemotherapies with cisplatin or carboplatin, gemcitabine, paclitaxel plus carboplatin, gemcitabine plus doxorubicin, and interferon- $\alpha$ [2-5]. Only 1 prospective phase II study in this setting has been published, and it seemed to indicate a better activity of the cisplatin-gemcitabine regimen [7]. In this French multicenter study $[3,7]$ platinum-gemcitabine induced transient clinical benefit in $65 \%$ of 20 cases, with $25 \%$ partial responses and $40 \%$ stable diseases, but only $48 \%$ of patients were alive 1 year after the start of therapy. In 3 relatively large retrospective series [8-10], including 1 Japanese study, the disease was seen predominantly in men above the age of 50 years, with a median size of primary renal tumor of $\sim 6-8 \mathrm{~cm}$, but with the majority of patients at presentation already having locally advanced disease or metastases. The role of radical nephrectomy, often performed even in the presence of disseminated disease, has not shown clear clinical benefit and remains controversial.

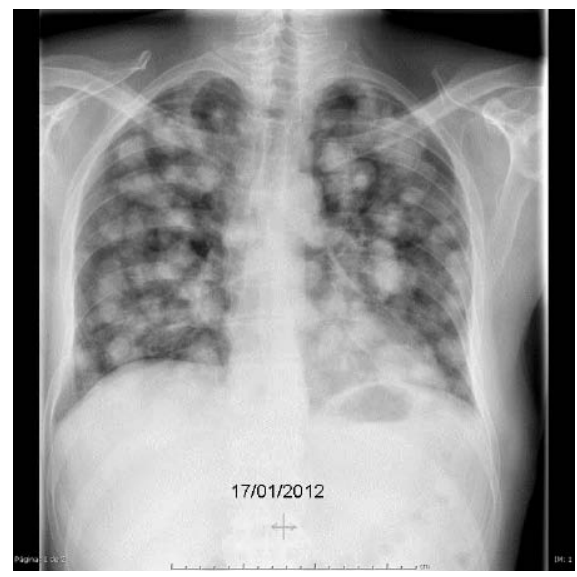

Fig. 1. Chest X-ray at presentation, with countless bilateral lung metastases in a critically ill patient.

\section{Case Report}

On admission our patient was very distressed and breathless and reported to have lost some $10 \mathrm{~kg}$ in weight over a few weeks. He had significant polydypsia and polyuria, with blurred vision and increasing difficulties in standing up and moving about. His performance status was poor with an ECOG (Eastern Cooperative Oncology Group) grade of 3. His chest X-ray showed countless metastases in both lung fields (fig. 1), his bone scintigram confirmed multiple hotspots compatible with metastases in his right hip, pelvic bones and axial skeleton. Multiple brain metastases were detected by both computed tomography (CT) scan and magnetic resonance imaging (MRI) of the brain, with lesions in posterior fossa, both hemispheres and pituitary-hypothalamus, but no signs of midline displacement or hydrocephalus. A body CT scan showed a renal mass in his left kidney, measuring $\sim 8 \mathrm{~cm}$ in diameter (fig. 2). An ultrasound guided biopsy was taken of this renal mass and histopathology was compatible with a high-grade CDC as confirmed by 2 independent expert histopathologists.

The following molecular studies were carried out on paraffin-embedded tissue from this biopsy sample: fluorescence in situ hybridization (FISH) with HER2 FISH pharmDx from DAKO and a Vysis PathVysion DNA probe kit (Abbott Molecular Inc., Abbott Park, IL, USA); V600E BRAF mutation analysis of exon 15 with kit-BRAF StripAssay (ViennaLab, Vienna, Austria); and ALK-translocation FISH with a Vysis LSI ALK Dual Color Break-apart rearrangement Probe-Hy Set (Abbot). These molecular tests showed that the BRAF gene was wild type and that there was no ALK translocation, but HER2 (human epidermal growth factor receptor 2) was markedly overexpressed as shown by both FISH and immunohistochemistry (Herceptest score 3+).

On the grounds of the clinical and radiological suspicion of diabetes insipidus, he was started on desmopressin. Because of a rapidly deteriorating general condition and uncontrolled symptoms, he received palliative radiotherapy to his right hip and started whole brain radiotherapy ( $30 \mathrm{~Gy}$ in 10 fractions plus 6 Gy boost over pituitary in 3 fractions) and concomitant systemic antitumor therapy with oral capecitabine $(1,250 \mathrm{mg} /$ $\mathrm{m}^{2}$ every $12 \mathrm{~h}$ for 2 weeks out of every 3 weeks). After radiotherapy, a control MRI of the brain showed some disease progression and the patient continued therapy with capecitabine 3 times weekly (at the same dose) plus intravenous trastuzumab $(8 \mathrm{mg} / \mathrm{kg}$ loading dose followed by $6 \mathrm{mg} / \mathrm{kg}$ intravenously every 3 weeks) plus oral lapatinib (750 mg/day to reduce risks of severe diarrhea) and intravenous zoledronic acid (4 mg). Treatment was very well tolerated and the patient's symptoms (shortness of breath, extreme fatigue, pain, excessive thirst, and blurred vision) rapidly improved so that after only the second course of this therapy the patient was already up and about the ward. The patient remains alive and well at his home, 7 months after initiation of therapy, with an ECOG performance status of 1 . His primary tumor in the kidney and most metastatic sites (figs. 3 and 4) continue to shrink to this date. He is tolerating treatment extremely well, except for some mild intermittent diarrhea and fatigue.
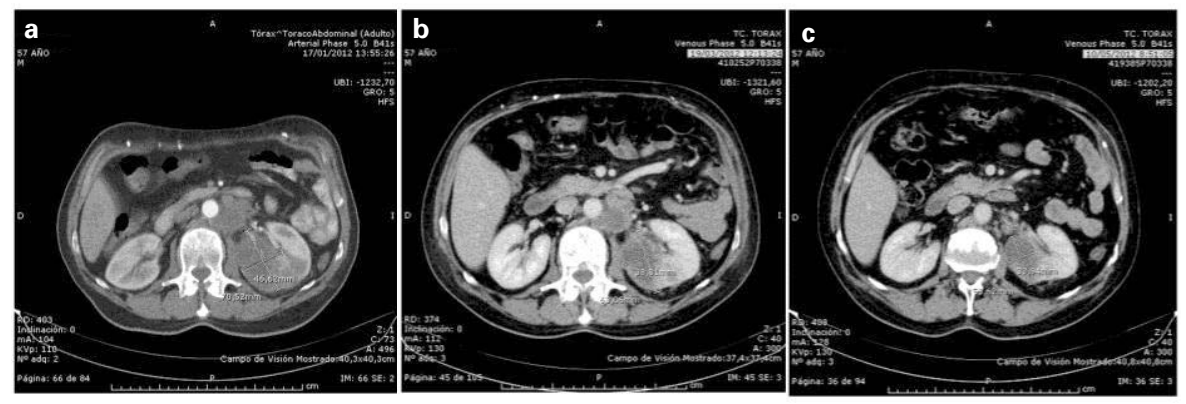

Fig. 2. a-c CT scans of the abdomen showing a renal mass in the left kidney, prior to therapy, and after 2 and 4 months after systemic treatment with double HER2 blockade and oral capecitabine. 
Fig. 3. a-c CT scans of the chest prior to and following systemic therapies, showing sequential changes in the diameters of some of the largest of the bilateral lung metastasis.
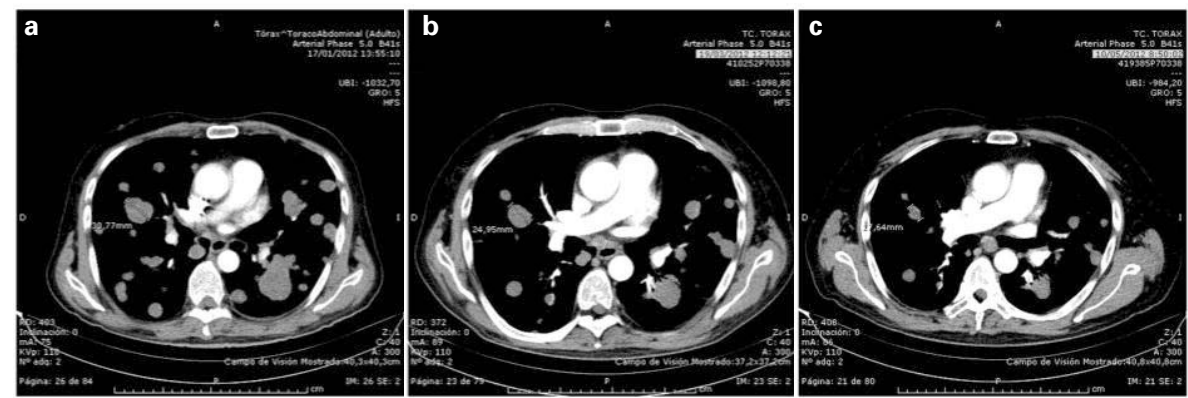

Fig. 4. Sequential MRI images of the brain (posterior fossa) at diagnosis (left), following whole brain radiotherapy and concomitant oral capecitabine (center, showing some increase in size), and following therapy with double blockade of HER2 and oral capecitabine (right) with an excellent response in the central nervous system.

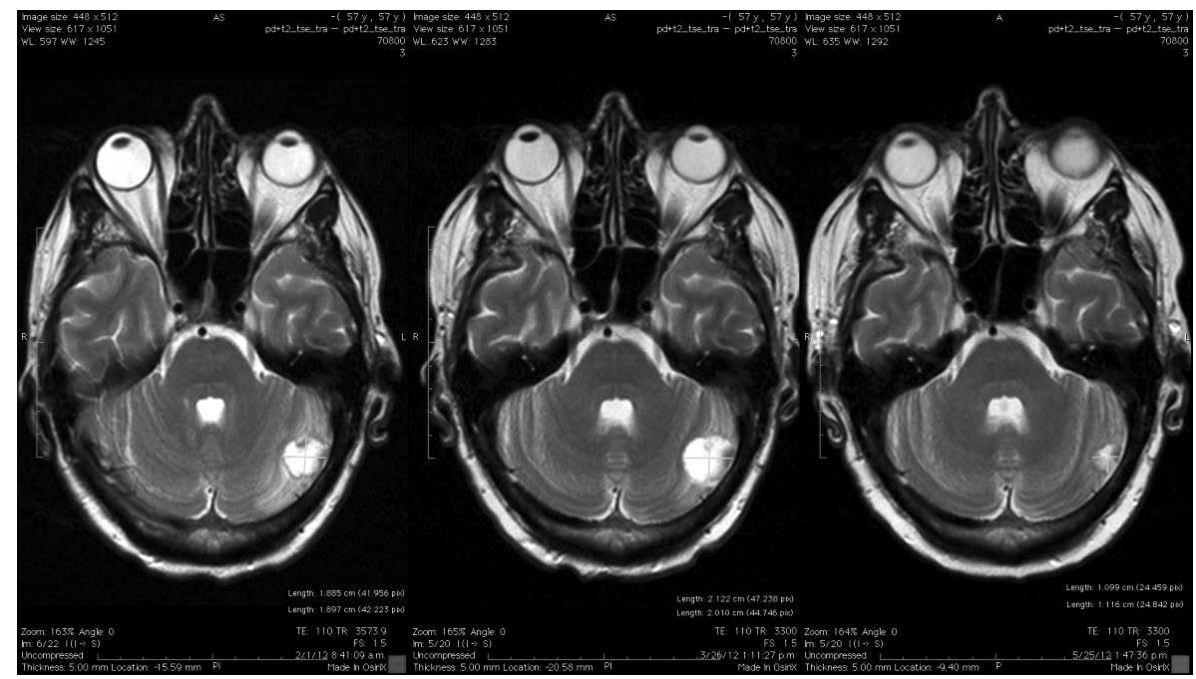

\section{Discussion}

In recent years several small studies or single case reports have suggested a variable degree of tumor responses to targeted therapies, including sorafenib, sunitinib and temsirolimus [11-13], most of them only partial and short-lived. In a recent Spanish series of 6 patients, none of these treatments appeared to be effective [14], and the median survival was only 5.5 months with only 2 patients, both with localized disease at diagnosis, surviving for longer than 1 year. In a retrospective analysis of 7 cases [5], 4 patients received firstline treatment with sorafenib, 1 with sunitinib and 2 with temsirolimus, and following progression 2 patients received second-line treatment with sunitinib. Unfortunately, 5 of these 7 patients developed early progression of disease, surviving only 4 months, and only 2 survived for more than 1 year. The authors concluded that further studies including biomarkers as predictive factors of tumor biology and clinical features are required to improve the management of this challenging disease [5].

To our knowledge, the only 'druggable' molecular target identified so far in a small Italian retrospective evaluation is HER2 oncogene, whose amplification, as detected by competitive PCR [15], was clearly related to poorer prognosis. In this small retrospective study, dating back to 1997, 11 CDC cases were studied by PCR, and HER2 oncogene amplification was present in 5 out of 11 cases $(45 \%)$ with the number of copies ranging from 4 to 12 . All patients presenting amplification of this oncogene died within 1 year (between 4 and 12 months) after surgery, while of the 6 patients without amplification at least $50 \%$ survived for longer than 3 years, suggesting that HER2 overexpression might indeed be relevant to prognosis and clinical behavior, and perhaps the tumor biology itself. No other specific molecular markers have yet been reported.

Several recent reports have indicated the clinical benefit of double HER2 blockade in breast cancer [16-18] and of oral lapatinib in the treatment of brain metastases in breast cancer patients $[19,20]$. The rationale is the synergistic activity of double HER2 blockade on overexpressing tumor cells, and that lapatinib, being a small molecular weight oral tyrosine kinase inhibitor, should be capable of better penetrating the blood-brain barrier than trastuzumab, particularly in the context of brain metastases after brain radiotherapy. The triple combination of oral capecitabine, intravenous trastuzumab and oral lapatinib was very well tolerated by our patient and is probably quite suitable to patients with bad performance status. Dual inhibition of HER2 in breast cancer treatment has recently shown promise, and may well be also useful in other cancers overexpressing this receptor [21, 22]. 
To our knowledge the clinical case presented here is the first clinical report of safe and effective therapy in this rare form of cancer (CDC or Bellini's tumor), based on a wellknown cancer marker (HER2) and its overexpression. It seems highly unlikely that this very good systemic response in our patient was due to oral capecitabine alone, as brain metastases had actually increased in both number and size, following 1 course of oral capecitabine and concomitant whole brain radiotherapy. However, a synergistic effect of oral capecitabine with double HER2 blockade cannot be ruled out. Further studies are urgently warranted.

\section{Disclosure Statement}

The authors declare no conflicts of interest.

\section{References}

1 Srigley JR, Eble JN. Collecting duct carcinoma of the kidney. Semin Diagn Pathol 1998;15:54-67.

$\checkmark 2$ Milowsky MI, Rosmarin A, Tickoo SK, et al. Active chemotherapy for collecting duct carcinoma of the kidney: A case report and review of the literature. Cancer 2002;94:111-116.

3 Oudard S, Banu E, Vieillefond A, et al. Prospective multicenter phase II study of gemcitabine plus platinum salt for metastatic collecting duct carcinoma: Results of a GETUG (Groupe d'Etudes des Tumeurs Uro-Génitales) study. J Urol 2007;177: 1698-1702.

4 Peyromaure M, Thiounn N, Scotté F, et al. Collecting duct carcinoma of the kidney: A clinicopathological study of 9 cases. J Urol 2003;170:1138-1140

5 Procopio G, Verzoni E, Iacovelli R, et al. Is there a role for targeted therapies in the collecting ducts of Bellini carcinoma? Efficacy data from a retrospective analysis of 7 cases. Clin Exp Nephrol 2012; 16:464-467.

6 Kovacs G, Akhtar M, Beckwith BJ, et al. The Heidelberg classification of renal cell tumours J Pathol 1997;183:131-133.

7 Culine S, Oudard S, Duclos B, et al. A phase II prospective study of gemcitabine and platin-based combination as first-line chemotherapy for metastatic Bellini duct carcinoma patients. Results of GETUG study. J Clin. Oncol. 2005;23:4543.
Tokuda N, Naito S, Matsuzaki O, et al. Collecting duct (Bellini duct) renal cell carcinoma: A nationwide survey in Japan. J Urol 2006;176:40-43.

$\checkmark 9$ Karakiewicz PI, Trinh QD, Rioux-Leclercq N, et al. Collecting duct renal cell carcinoma: A matched analysis of 41 cases. Eur Urol 2007;52:1140-1146.

10 Wright JL, Risk MC, Hotaling J, et al. Effect of collecting duct histology on renal cell cancer outcome. J Urol 2009;182:2595-2600.

11 Miyake H, Haraguchi T, Takemaka A, et al. Metastatic collecting duct carcinoma of the kidney responded to sunitinib. Int J Clin Oncol 2011;16:153155.

12 Mego M, Sycova-Mila Z, Rejlekova K, et al. Sunitinib in the treatment of tubulocystic carcinoma of the kidney. A case report. Ann Oncol 2008;19:1655-1661.

13 Lee JL, Ahn JH, Lim HY, et al. Multicenter phase II study of sunitinib in patients with non-clear cell renal cell carcinoma. Ann Oncol 2012;23:21082114.

14 Husillos A, Herranz-Amo F, Subirá D, et al. Carcinoma de células renales del túbulo colector. Actas Urol Españolas 2011;35:368-371.

15 Selli C, Amorosi A, Vona G, et al. Retrospective evaluation of c-erbB-2 oncogene amplification using competitive PCR in collecting duct carcinoma of the kidney. J Urol 1997;158:245-247.
16 Blackwell KL, Burstein HJ, Storniolo AM, et al. Randomized study of lapatinib alone or in combination with trastuzumab in women with ErbB2positive, trastuzumab-refractory metastatic breast cancer. J Clin Oncol 2010;28:1124-1130.

17 Blackwell KL, Burstein H, Sledge G, et al. Updated survival analysis of a randomized study of lapatinib alone or in combination with trastuzumab in women with HER2-positive metastatic breast cancer progressing on trastuzumab therapy. Cancer Res 2009:69(24 Suppl):Abstract 61.

18 Baselga J, Bradbury I, Eidtmann H, et al. Lapatinib with trastuzumab for HER2-positive early breast cancer (NeoALTTO): A randomised, open-label, multicentre, phase 3 trial. Lancet 2012;379:633-640.

19 Azim HA. Systemic treatment of brain metastases in HER2-positive breast cancer. Future Oncol. 2012;8:135-144.

20 Bartsch R, Berghoff A, Pluschnig U, et. al. Impact of anti-HER2 therapy on overall survival in HER2overexpressing breast cancer patients with brain metastases. Br J Cancer 2012;106:25-31.

21 Baselga J, Cortes J, Kim S-B, et al. Pertuzumab plus trastuzumab plus docetaxel for metastatic breast cancer. N Engl J Med 2012;366:109-119.

22 Gnant M, Steger G. Dual inhibition of HER2 in breast cancer treatment. Lancet 2012;379:596-598. 